\title{
Defects in $\mathrm{Cu}_{2} \mathrm{O}$ studied by deep level transient spectroscopy
}

\author{
G. K. Paul, Y. Nawa, H. Sato, T. Sakurai, and K. Akimoto ${ }^{a)}$ \\ Institute of Applied Physics, University of Tsukuba, 1-1-1 Tennodai, Tsukuba, Ibaraki 305-8573, Japan
}

(Received 31 August 2005; accepted 4 January 2006; published online 3 April 2006)

\begin{abstract}
Hole traps in $p$-type $\mathrm{Cu}_{2} \mathrm{O}$ were studied by means of deep level transient spectroscopy in the heterostructure of $p-\mathrm{Cu}_{2} \mathrm{O} / i-\mathrm{ZnO} / n-\mathrm{ZnO}$. In addition to the trap level at about $0.45 \mathrm{eV}$ from the valance band edge, which is already reported as being due to $\mathrm{Cu}$ vacancy, we found a new trap level at about $0.25 \mathrm{eV}$. The new trap is tentatively assigned as $\mathrm{Cu}$-di-vacancy from the trap concentration dependence on oxygen flow rate and substrate temperature. (C) 2006 American Institute of Physics. [DOI: 10.1063/1.2175492]
\end{abstract}

Cuprous oxide $\left(\mathrm{Cu}_{2} \mathrm{O}\right)$, a direct band gap semiconductor with a band gap energy of $2.0 \mathrm{eV}$, has been regarded as one of the most promising materials for application to photovoltaic cells, ${ }^{1,2}$ especially for the top cell in a tandem structure. The attractiveness of $\mathrm{Cu}_{2} \mathrm{O}$ as a photovoltaic material lies in the fact that the constituent materials are nontoxic, low cost and abundantly available. $\mathrm{Cu}_{2} \mathrm{O} / \mathrm{ZnO}$ heterojunction has been fabricated by radio frequency (rf) magnetron sputtering and showed the photovoltaic effects, but did not demonstrate good performance. ${ }^{3}$ Knowledge of defect energies as well as their densities is an important input for further improvement of the performance of $\mathrm{Cu}_{2} \mathrm{O}$ thin film polycrystalline solar cells. There are several reports on the deep trap in $\mathrm{Cu}_{2} \mathrm{O}$ by measuring deep level transient spectroscopy (DLTS). ${ }^{4-6} \mathrm{~A}$ hole trap with the activation energy of about $0.45 \mathrm{eV}$ from the valence band edge has been observed and assigned as $\mathrm{Cu}$ vacancy using Schottky diodes. However, the temperature range in the DLTS measurements was too narrow. It is necessary to measure the DLTS in the expanded temperature range in order to understand the origin of the defect in $\mathrm{Cu}_{2} \mathrm{O}$. In this work, the DLTS spectra of $\mathrm{Cu}_{2} \mathrm{O}$ with the junction of $n-\mathrm{ZnO} / i-\mathrm{ZnO} / p-\mathrm{Cu}_{2} \mathrm{O}$ structure in the temperature range between 100 and $350 \mathrm{~K}$ is reported. We observed a new trap with the activation energy of $0.25 \mathrm{eV}$ from the valence band edge in addition to the $0.45 \mathrm{eV}$ trap, and the origin of the $0.25 \mathrm{eV}$ trap is discussed based on the sample preparation conditions.

Polycrystalline $p-\mathrm{Cu}_{2} \mathrm{O} / n-\mathrm{ZnO}$ heterostructure was grown by means of rf magnetron sputtering on Corning 7059 glass substrate using a $\mathrm{Cu}$ target of $99.99 \%$ purity, $\mathrm{ZnO}$ target and Ar as sputtering gas. Oxygen was introduced during the growth of $\mathrm{Cu}_{2} \mathrm{O}$ through a nozzle whose end was placed near the substrate. We prepared two sets of samples for $\mathrm{Cu}_{2} \mathrm{O}$, with various oxygen flow rates (Sample 1: $140 \mathrm{ml} / \mathrm{min}$, Sample 2: $155 \mathrm{ml} / \mathrm{min}$, Sample 3: $163 \mathrm{ml} / \mathrm{min}$, Sample 4: $173 \mathrm{ml} / \mathrm{min}$ ) and another set with various substrate temperatures (Sample I: $570 \mathrm{~K}$, Sample II: $670 \mathrm{~K}$, Sample III: $720 \mathrm{~K}$, Sample IV: $770 \mathrm{~K})$. At the interface between $n-\mathrm{ZnO}$ and $p-\mathrm{Cu}_{2} \mathrm{O}$, intrinsic $\mathrm{ZnO}(i-\mathrm{ZnO})$ layer was deposited. The $i-\mathrm{ZnO}$ and $n-\mathrm{ZnO}$ were deposited using undoped and $1 \mathrm{wt} \% \mathrm{Al}_{2} \mathrm{O}_{3}$ doped $\mathrm{ZnO}$ target, respectively. The thickness of each layer was 800, 100, and $1700 \mathrm{~nm}$ for $n-\mathrm{ZnO}, i-\mathrm{ZnO}$ and $p-\mathrm{Cu}_{2} \mathrm{O}$, respectively. The hole concentration of $\mathrm{Cu}_{2} \mathrm{O}$ was in the range between $1 \times 10^{16}$ and

\footnotetext{
a)Electronic mail: akimoto@esys.tsukuba.ac.jp
}

$4 \times 10^{17} \mathrm{~cm}^{-3}$, and the electron concentration of $n-\mathrm{ZnO}$ was kept constant at $1 \times 10^{20} \mathrm{~cm}^{-3}$. Ohmic contacts were performed on $\mathrm{Cu}_{2} \mathrm{O}$ by thermal evaporation of gold $(\mathrm{Au})$ with the diameter of $0.3 \mathrm{~mm}$. The schematic heterostructure is shown in Fig. 1.

The structural properties were studied by x-ray diffraction (XRD) in the $\theta-2 \theta$ mode using $\mathrm{Cu} K \alpha$ radiation. The capacitance-voltage $(C-V)$ measurements were performed on these samples with the modulation frequency of $1 \mathrm{MHz}$. DLTS measurements were performed with the reverse bias voltage between 0 and $-0.5 \mathrm{~V}$, with the pulse width and duration of 0.1 and $50 \mathrm{~ms}$, respectively. By scanning the transient capacitance change over a wide range of temperatures under various rate windows, the hole emission rate $e_{p}$ as a function of inverse temperature $\left(T^{-1}\right)$ can be obtained. From the Arrhenious plot (i.e., $\ln \left(T^{2} \tau\right)$ vs $T^{-1}$, where $\left.\tau=1 / e_{p}\right)$, the activation energy $E_{a}$ of the defect level was extracted. ${ }^{7}$ The hole emission rate is related to the capture cross section and activation energy of the trap level expressed as

$$
e_{p}=s_{p} \nu_{\mathrm{th}} N_{v} \exp \left(-E_{a} / k T\right),
$$

where, $s_{p}$ is the capture cross section, $\nu_{\text {th }}$ is the hole thermal velocity, $N_{v}$ is the effective density of state of the valence band and $k$ is the Boltzmann's constant. The value of $N_{v}$ was calculated to be $1.7 \times 10^{19} \mathrm{~cm}^{-3}$ using the effective hole mass of $0.8 \mathrm{~m}_{0}{ }^{8}$ The hole trap density, $N_{T}$, can be calculated by using the expression

$$
N_{T}=\left(2 \Delta C / C_{0}\right) N_{a} .
$$

The acceptor concentration, $N_{a}$, is determined by $C$ - $V$ measurements, which give the average acceptor concentration in the $\mathrm{Cu}_{2} \mathrm{O}$ layer. $C_{0}$ is the zero bias capacitance that is ob-

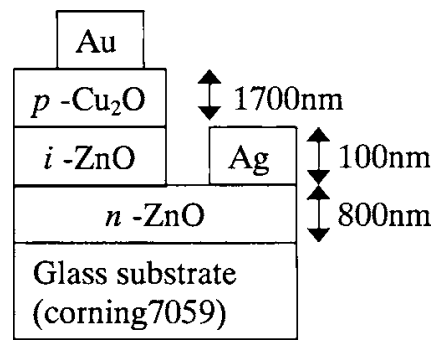

FIG. 1. Schematic structure of $n-\mathrm{ZnO} / i-\mathrm{ZnO} / p-\mathrm{Cu}_{2} \mathrm{O}$ for DLTS measurements. 


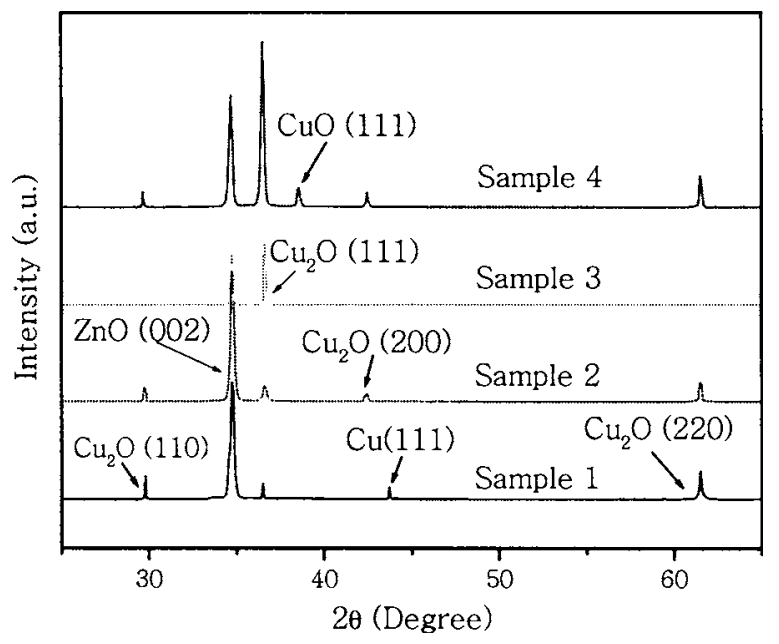

FIG. 2. XRD profiles of $n-\mathrm{ZnO} / i-\mathrm{ZnO} / p-\mathrm{Cu}_{2} \mathrm{O}$ heterostructure with the oxygen flow rate of $140,155,163$, and $173 \mathrm{ml} / \mathrm{min}$.

tained from the $C-T$ data at the corresponding DLTS peak temperature.

The XRD profiles in $\theta-2 \theta$ mode using $\mathrm{Cu} K \alpha$ radiation of the heterostructures from Sample 1 to Sample 4 are shown in Fig. 2. Diffraction peaks of (110), (111), (200) and (220) planes of $\mathrm{Cu}_{2} \mathrm{O}$ are observed. We found a small intensity of $\mathrm{Cu}$ (111) diffraction peak for low $\mathrm{O}_{2}$ flow sample (Sample 1) and $\mathrm{CuO}(111)$ for high $\mathrm{O}_{2}$ flow sample (Sample 4). It is clear that the samples prepared in this study contain oxygen deficient $\mathrm{Cu}_{2} \mathrm{O}$ and oxygen excess $\mathrm{Cu}_{2} \mathrm{O}$.

The $C-V$ measurements on the heterostructure of $\mathrm{Cu}_{2} \mathrm{O} / \mathrm{ZnO}$ were carried out at room temperature. The relation between $1 / C^{2}$ and $V$ was basically expressed by a straight line. These results indicate that the depletion region increases with increasing the applied voltage and the value of the capacitance is not so affected by the existence of the heterointerface of $\mathrm{ZnO} / \mathrm{Cu}_{2} \mathrm{O}$. This means that the signal of the capacitance only comes from $\mathrm{Cu}_{2} \mathrm{O}$ layer.

A typical DLTS spectrum of Sample 4 is shown in the inset of Fig. 3. Two clear hole traps were observed for all samples. Only one trap has been reported in $\mathrm{Cu}_{2} \mathrm{O}$ by DLTS measurements in the temperature range between 200 and $300 \mathrm{~K}$. We expanded the temperature range of the DLTS measurements between 100 and $350 \mathrm{~K}$ and a new hole trap at around $140 \mathrm{~K}$ denoted as trap A in the inset of Fig. 3 was observed. The trap B in the inset of Fig. 3 was observed in

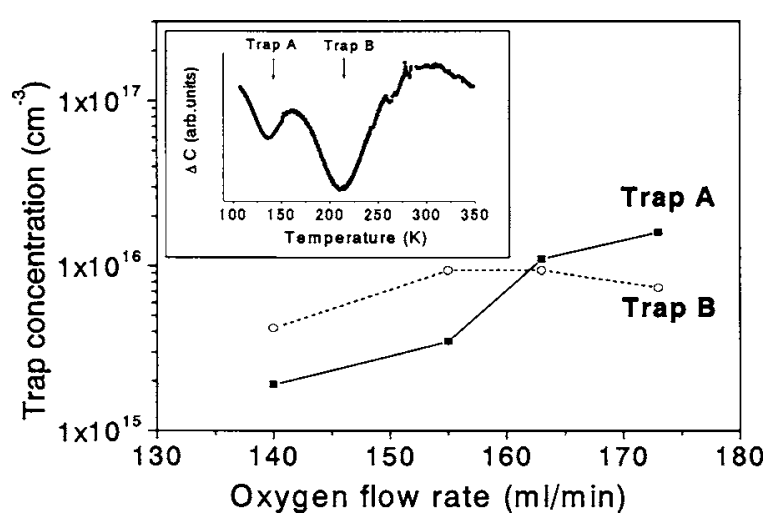

FIG. 3. Relationship between trap concentration and oxygen flow rate. A typical DLTS spectrum of Sample 4 is shown in the inset. The reverse bias, filling pulse and the pulse width were $-0.5 \mathrm{~V}, 0 \mathrm{~V}$ and $0.1 \mathrm{~ms}$, respectively. Downloaded 20 Dec 2009 to 130.158 .56186 . Redistribution subject

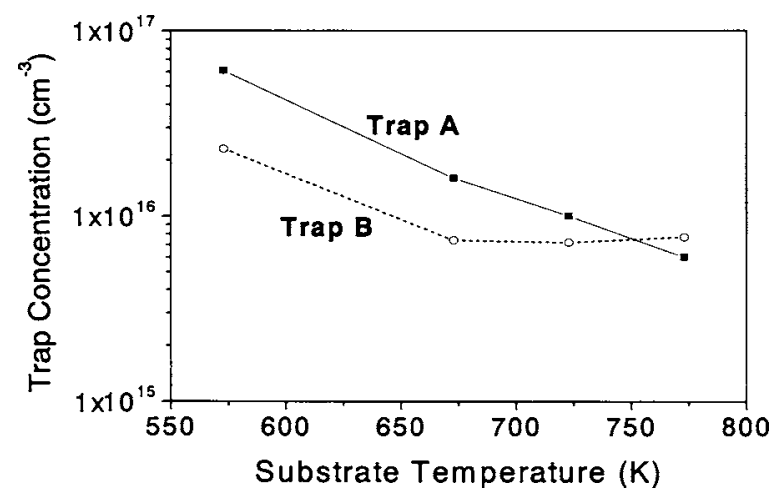

FIG. 4. Relationship between trap concentration and substrate temperature

the same temperature range as reported. The average activation energy of the trap B was calculated to be $0.45 \mathrm{eV}$ from the Arrhenius plots. Judging from the activation energy and the pre-exponential factor in the Arrhenius plots, trap B is the same as that reported, which is assigned as $\mathrm{Cu}$ vacancy. ${ }^{9-13}$ The assignment is completely consistent with that obtained theoretically. ${ }^{14}$

The average activation energy of trap A was calculated to be $0.25 \mathrm{eV}$. To consider the origin of trap A, the relationship between the trap concentration and oxygen flow rate during growth was studied, and the results are shown in Fig. 3. The concentration of trap A increased with increasing oxygen flow rate, on the other hand the concentration of trap $\mathrm{B}$ slightly increased and then slightly decreased. The dominant trap changed from trap B to trap A with increasing oxygen flow rate. We can expect that the concentration of $\mathrm{Cu}$ vacancy and interstitial oxygen increased with increasing oxygen flow rate. Therefore, oxygen interstitial may be one of the candidates for trap A, although it is not clear that the interstitial oxygen can act as an acceptor. A more plausible candidate for the trap A may be $\mathrm{Cu}$ vacancy complex like $\mathrm{Cu}$-di-vacancy, since the concentration of trap $\mathrm{B}$ tends to decrease even in the strong condition of $\mathrm{Cu}$ deficiency which is confirmed by x-ray diffraction as shown in Fig. 2. It may be reasonable to consider that the formation of $\mathrm{Cu}$-divacancy is enhanced with increasing the concentration of $\mathrm{Cu}$-mono-vacancy and dominant defect changes from monovacancy to di-vacancy with increasing vacancy concentration. The trap level of the di-vacancy may be shallower than that of the mono-vacancy because of the vacancy-vacancy interaction as discussed theoretically. ${ }^{14}$ The activation energy of trap A $(0.25 \mathrm{eV})$ is shallower than that of trap B $(0.45 \mathrm{eV})$, so the $\mathrm{Cu}$-di-vacancy is a strong candidate for the trap A.

We also studied the deep trap in the $\mathrm{Cu}_{2} \mathrm{O}$ with the effect of substrate temperature. The samples also showed trap A and trap B in DLTS spectra. The relationship between the trap concentration and the substrate temperature is shown in Fig. 4. The concentration of both trap A and B decreased with increasing substrate temperature, and dominant trap was trap A for relatively lower substrate temperature and it changed to trap B at higher temperature, as shown in Fig. 4. As reported earlier, the crystal quality of $\mathrm{Cu}_{2} \mathrm{O}$ was improved by increasing substrate temperature. ${ }^{15}$ For example, carrier concentration of undoped $\mathrm{Cu}_{2} \mathrm{O}$ and the value of the full width at half maximum of $\mathrm{x}$-ray diffraction peaks decreased, and the hole mobility increased with increasing substrate temperature. These results indicate that the defect deno AlP license or copyright; see http://apl.aip.org/apl/copyright.jsp 
sity in $\mathrm{Cu}_{2} \mathrm{O}$ decreased with increasing substrate temperature. The results shown in Fig. 4 are consistent with the previously reported results.

When the trap concentration is relatively high, trap A is dominant, and when the trap concentration is relatively low, trap B is dominant. This tendency was also observed in Fig. 3. As discussed on Fig. 3, we consider that the $\mathrm{Cu}-$ mono-vacancy is mainly generated when the vacancy concentration is relatively low and when the vacancy concentration exceeds a threshold value, Cu-di-vacancy becomes dominant. If this process is true, the variation of the trap concentration with substrate temperature shown in Fig. 4 is reasonably well understood. That is, when the defect density is high due to lower substrate temperature, trap $\mathrm{A}(\mathrm{Cu}$-divacancy) is dominant. When the defect density is low due to higher substrate temperature, trap $\mathrm{B}$ (Cu-mono-vacancy) is dominant. The variation of the defect density with the growth condition seems to be consistent with the proposed defect model.

In conclusion, DLTS measurements were performed for $\mathrm{Cu}_{2} \mathrm{O}$ with the $\mathrm{Cu}_{2} \mathrm{O} / \mathrm{ZnO}$ heterostructure and two kinds of hole traps were detected. One of the traps (trap A) whose activation energy is $0.25 \mathrm{eV}$ was observed. The density of trap $A$ increased with increasing $\mathrm{O}_{2}$ flow rate during the growth. Trap A is tentatively assigned as Cu-di-vacancy. The origin of the other trap whose activation energy is $0.45 \mathrm{eV}$ may be $\mathrm{Cu}$-mono-vacancy consistent with the results reported earlier.

${ }^{1}$ L. C. Olsen and Bohara, 11th IEEE Photovoltaic Specialists Conference Records, 1975 , p. 381

${ }^{2}$ L. Papadimitriou, N. A. Economou, and D. Trivich, Sol. Cells 3, 73 (1981).

${ }^{3}$ J. Herion, A. Niekisch, and G. Scharl, Sol. Energy Mater. 4, 101 (1980).

${ }^{4}$ L. Papadimitriou, Solid-State Electron. 36, 431 (1993).

${ }^{5}$ D. V. Lang, J. Appl. Phys. 45, 3023 (1974)

${ }^{6}$ H. S. Reehal, M. P. Lesnaik, and A. E. Hughes, J. Phys. D 29, 934 (1996).

${ }^{7}$ D. K. Schroder, Semiconductor Material and Device Characterization (Wiley, New York, 1998).

${ }^{8}$ E. F. Gross and I. Pastrnyak, Sov. Phys. Solid State 1, 466 (1959).

${ }^{9}$ L. Papadimitriou and N. A. Economou, J. Cryst. Growth 64, 604 (1983).

${ }^{10}$ J. A. Assimos and D. Trivich, Phys. Status Solidi A 26, 477 (1974).

${ }^{11}$ M. Tapiero, J. P. Zielinger, and C. Noguest, Phys. Status Solidi A 12, 517 (1972).

${ }^{12}$ C. Noguest, M. Tapiero, and J. P. Zielinger, Phys. Status Solidi A 24, 565 (1974)

${ }^{13}$ N. L. Peterson and C. L. Wiley, J. Phys. Chem. Solids 45, 281 (1984).

${ }^{14}$ A. F. Wright and J. S. Nelson, J. Appl. Phys. 92, 5849 (2002).

${ }^{15}$ S. Ishizuka, T. Maruyama, and K. Akimoto, Jpn. J. Appl. Phys., Part 2 39, L786 (2000). 